\title{
Protective effect of Urtica dioica in liver and kidney damages induce by ethylene glycol in rabbits: A histopathological study
}

\author{
M.A. Al-Akash ${ }^{\circledR}$, H.A. Rajab ${ }^{\circledR}$ and I.N. Al-Assaf ${ }^{\circledR}$ \\ Mosul Technical Institute, Northern Technical University, Mosul, Iraq
}

\begin{tabular}{l} 
Article information \\
\hline Article history: \\
Received February 20, 2021 \\
Accepted May 04, 2021 \\
Available online November 22, 2021 \\
\hline Keywords: \\
Ethylene glycol \\
Urtica dioica \\
Antioxidants \\
Calcium oxalate \\
Rabbits \\
\hline Correspondence: \\
M.A. Al-Akash \\
motaz78@ntu.edu.iq
\end{tabular}

\begin{abstract}
Urtica dioica is used in the many countries as seasoning and as an herbal medicine (antioxidant). In this study, adult male locale rabbit was separated into five groups, group 1 considered as control, group 2 to 5 animals were treated with $0.75 \%$ ethylene glycol (EG) in water to induce renal and liver damage till $30^{\text {th }}$ day. The group 3 to 5 animals were feed extract of the plant of $U$. dioica at a dosage of $100 \mathrm{mg} / \mathrm{kg}$ body weight from day 15 to the day 30. The extracts were administered twice daily orally. Liver histopathological changes characterized by vacuolar degeneration and coagulative necrosis of hepatocytes, congestion and dilatation of central vein and sinusoids. Renal histopathological changes characterized by deposition of oxalates, blood vessels congestion infiltration of inflammatory cells and change in renal glomeruli in GE treated groups. While histopathological changes in the animals group treated with $U$. dioica extract and ethylene glycol showed an increase improvement of the histological features of liver tissue, were limited dilatation of renal tubules with less deposition of oxalates, as well as slight infiltration of inflammatory cells in the interstitial tissue. Finally, as a conclusion we noticed that $U$. dioica extracts had the ameliorative effect of ethylene glycol-induced hepatic and renal histopathological.
\end{abstract}

DOI: 10.33899/ijvs.2021.129606.1666, (C)Authors, 2022, College of Veterinary Medicine, University of Mosul.

This is an open access article under the CC BY 4.0 license (http://creativecommons.org/licenses/by/4.0/).

\section{Introduction}

Ethylene glycol (EG) is a synthetic organic chemical material that is used in numerous commercial and industrial applications and characterized for being colorless, odorless and sweet testing. It is also used for other chemicals as a simple building element (1), moreover ethylene glycol utilized anti freezer, polyester fiber and polyester resins, made of asphalt emulsion paint, heat transfer factor and as solvent (2). Inflammation, renal damage and renal oxalate $(\mathrm{CaOx})$ may be caused by ethylene glycol.

By generating reactive oxygen species, such as superoxide and hydrogen peroxide $\left(\mathrm{H}_{2} \mathrm{O}_{2}\right) \mathrm{CaOx}$ causing oxidative harm (3). A significant step of urolithiasis is crystal adhesion that results in epithelial damage (i.e. formation of stones in the urinary tract). Often, $\mathrm{CaOx}-$ induced oxidative stress $(4,5)$. As time progresses, we become more aware of what nature contains as beneficial to our health, and with it our desire to learn more about these elements, one of these ancient elements in its existence, which has been talked about in recent research is the Stinging Nettle (Urtica dioica) has been a staple in herbal medicine since ancient times (6).

The major chemical constituents of $U$. dioica are volatile compounds, polysaccharides, sterols, proteins, tannins, flavonoids, isolectins, fatty acids, and terpenes, vitamins and minerals (7), has been reported to have various pharmacological activities like anti-inflammatory, antioxidant and hepatoprotective effects (8).

The aim of this study is to explain the histopathological changes induced by ethylene glycol on the rabbit's livers and kidneys, as well as the protective effects of $U$. dioica on these changes. 


\section{Material and methods}

Urtica dioica or Nettle was purchased from the local market as leaves. It was classified according to plant classification references related to medicinal plants (9). Also a voucher specimens of the plant was identified and authenticated at the herbariums of the Prof. Dr. Amer Mohsen, Department of Biology, College of Education for the Pure Science, University of Mosul.

\section{Preparation of extracts}

Preparation of flavonoids, glycosides and alkaloids extracts of $U$. dioica were done according to the method described by $(10,11)$.

\section{Animal grouping}

Local male rabbit's weightings between 700-800 gm were used, the animals were divided into five groups, each of which had three animals. Group 1 consider as control and maintained on regular laboratory diet and water ad labium. Group 2 to 5 animals were given $0.75 \%$ ethylene glycol (EG) in water till $30^{\text {th }}$ day (12). Group 3 to 5 animals were served as curative regimen and received flavonoids, glycosides and alkaloids extract of the plant of $U$. dioica dosage of $100 \mathrm{mg} / \mathrm{kg}$ body weight from day 15 to day 30 . The extracts were administered twice daily orally (13).

\section{Histopathology}

Tissue samples from the liver and kidney were taken and fixated in 10\% neutral buffer formalin solution for 72 $\mathrm{h}$, trimmed to sizes acceptable, washed by water, dehydrated with ascending concentration of ethyl alcohol, cleared in xylene, embedded in paraffin wax, sectioned by microtome at 5-6 $\mu \mathrm{m}$, stained with hematoxylin and eosin and examined under a light microscope $(14,15)$.

\section{Results}

\section{Liver}

The microscopic examination of the liver section of the rabbits treated with ethylene glycol for 30 days showed that the liver lost it is characteristic feature compared with control group (Figure 1A). The liver section of treated rabbits showed histological changes include vacuolar degeneration and hepatocyte coagulative necrosis (Figure 1B) congestion and dilatation of central vein and sinusoids (Figure 1C) focal infiltration of inflammatory cells (Figure 1D). infiltration of mononuclear inflammatory cells at the portal area (Figure 1E) as for the microscopic examination of the liver sections of the treated animals with ethylene glycol with $U$. dioica extract showed an improvement in the histological features of hepatic tissue which minimal to moderate penetration of inflammatory cells in liver tissue into the portal region (Figures 1F).

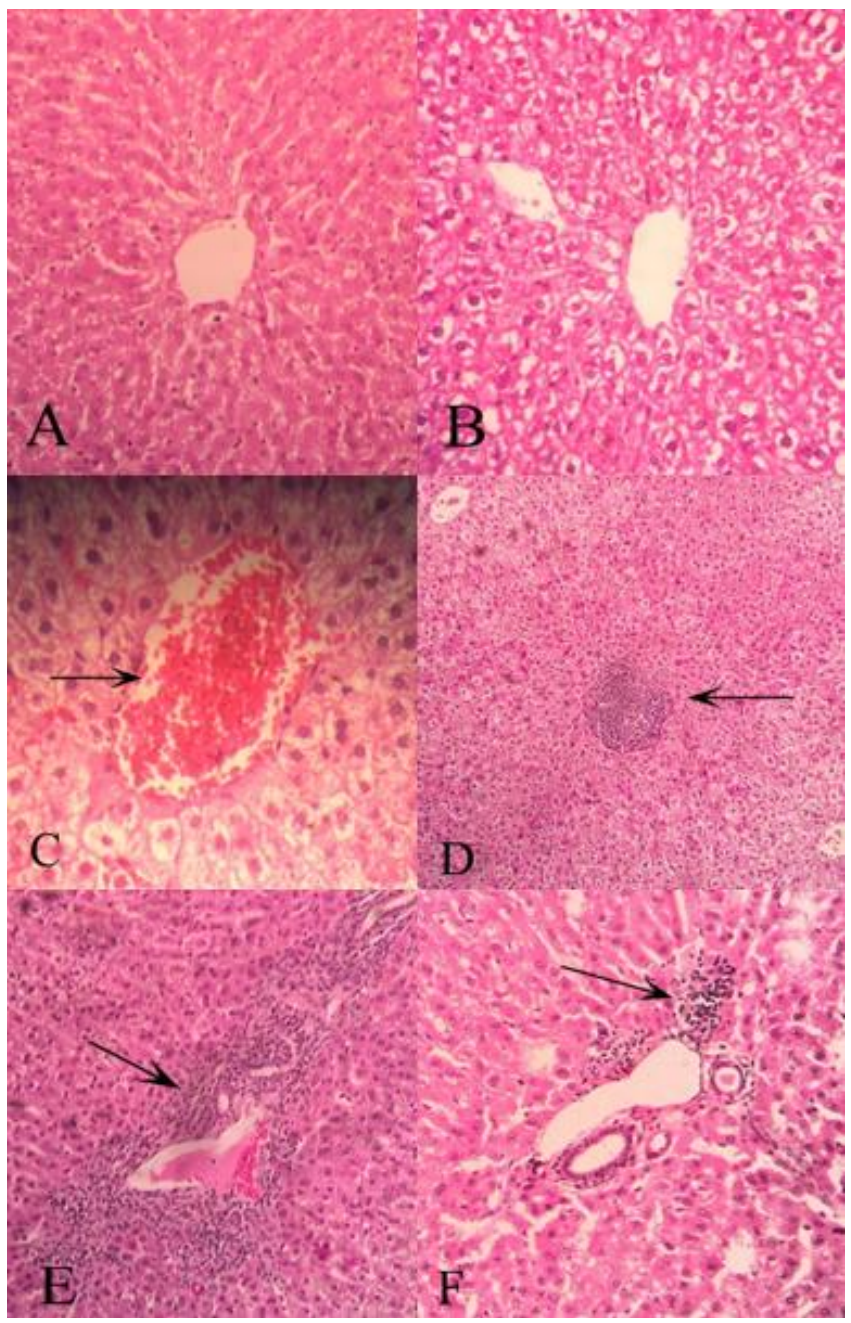

Figure 1A: Micrograph of the liver rabbits treated with ethylene glycol for 30 days showed that the liver lost it is characteristic feature (H\&E 4x). Figure 1B: The liver section of treated rabbits showed histological changes include vacuolar degeneration and coagulative necrosis of hepatocytes (H\&E 10x). Figure 1C: Congestion and dilatation of central vein and sinusoids (arrow) (H\&E 40x). Figure 1D: Focal infiltration of inflammatory cells (arrow) $(\mathrm{H} \& \mathrm{E} 4 \mathrm{x})$. Figure 1E: Infiltration of mononuclear inflammatory cells at the portal area (arrow) (H\&E 4x). Figure 1F: Treated animals with ethylene glycol with $U$. dioica extract showed minimal to moderate inflammatory cell infiltration in the portal region and in the hepatic tissue (arrow) (H\&E 4x,4x).

\section{Kidney}

The microscopic examination of the renal sections of the rabbits treated with ethylene glycol for 30 days showed increase in calcium and oxalate, deposition of crystals in the lumen of renal tubules (Figure 2A) focal infiltrations the inflammatory cells in the interstitial tissue (Figure 2B) 
congestion of the blood vessels at the interstitial tissue (Figure 2C) as well as the histological changes included the renal glomeruli (Figure 2D). As for the animal group treated with ethylene glycol and $U$. dioica extract showed a marked improvement in the histological feature of kidneys characterized by degenerative and necrotic changes of epithelial cells lining renal tubes with less deposition of oxalates (Figure 2E) as well as slight infiltration of inflammatory cells in the interstitial tissue (Figure 2F).

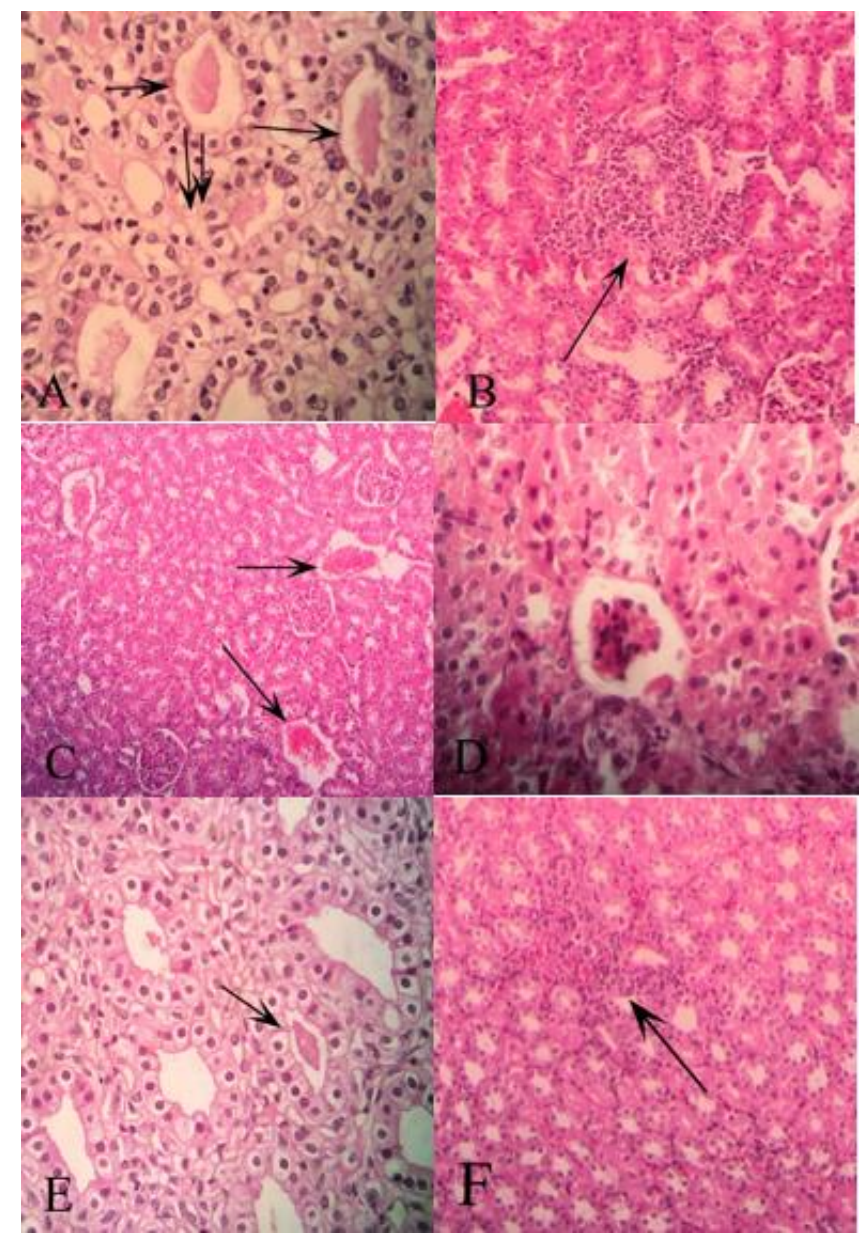

Figure 2A: Micrograph of the kidney rabbits treated with ethylin glycol for 30 days, oxalate accumulation in the lumen of renal tubules (arrow) (H\&E 10x). Figure 2B: Focal infiltrations of the inflammatory cells in the interstitial tissue (arrow) (H\&E 10x). Figure 2C: Congestion of the blood vessels at the interstitial tissue(arrow) (H\&E 4x). Figure 2D: Changes in the renal glomeruli (H\&E10x). Figure 2E: The kidney rabbits treated with ethylene glycol and $U$ dioica extract degenerative and necrotic changes of epithelial cells lining renal tubes with less deposition of oxalates (arrow) (H\&E 10x). Figure 2F: Light infiltration of inflammatory cells in the interstitial tissue (arrow) (H\&E 4x).

\section{Discussion}

The current study also showed eethylene glycol causes damage to liver tissue, such as vacuolar degeneration, hepatocyte coagulative necrosis and infiltration of mononuclear inflammatory cells, and this is similar to what was indicated (16), as well as increase in calcium and oxalate in kidney homogenate by ethylene glycol treatment in urolithiatic rabbits, it causes damage to the renal tissues and thus affects the kidney fails to perform its normal endocrine and metabolic functions, this will cause alteration in tubular function or structure affect glomerular function and vice versa (17). Also this occur due to deposition of oxalates in the lumen of the renal tubules which induced inflammatory reaction then leads to increase in the concentration of proteins (globulins and albumins) in the blood $(18,19)$. $U$. dioica have an ameliorative effect and reduction on kidney damage administration that was significantly attenuated. These results are consistent with what he indicated $(20,21)$, and that the decline in the amount of crystals. In addition to the percent inhibition of the formation of monohydrate crystals of calcium oxalate and calcium oxalate, was directly proportional to the rise in plant extract concentration (22). The $U$. dioica, extract has been demonstrated with a protecting enzymes and enhancing the properties of organs (23). A Significant injury was seen in a histopathological examination of the kidney. Ethylene glycol, which is treated with ethylene glycol, and crystal formation animals as compared to flavonoid-treated animals. The extract of that reverted and ameliorated the renal effect, and these findings were accepted with (24). As the kidney is a critical organ for the toxicity of ethylene glycol in laboratory animals, there is a histological modification of renal tissue recorded in this study. In our research, degeneration and necrosis, and calcium oxalate accumulation in the lumen of the renal tubules are consistently triggered by these changes (25).

\section{Conclusion}

we noticed that $U$. dioica extracts had the ameliorative effect of ethylene glycol-induced hepatic and renal histopathological.

\section{Acknowledgment}

The authors are very grateful to the Prof. Dr Amer Mohsen, University of Mosul, the College of Education for the Pure Science, Department of Biology, which helped to improve the quality of this work.

\section{Conflict of interest}

No conflicts. 


\section{References}

1. Staples CA, Williams JB, Craig GR, Roberts KM. Fate, effects and potential environmental risks of ethylene glycol: A review. Chemosphere. 2001;43(3):377-83. DOI: 10.1016/ -6535(00)00148-X

2. Song CH, Bae HJ, Ham YR, Na KR, Lee KW, Choi DE. A case of ethylene glycol intoxication with acute renal injury: successful recovery by fomepizole and renal replacement therapy. Electrolyte Blood Press. 2017;15(2):47-51. DOI: 10.5049/EBP.2017.15.2.47

3. Aslan Z, Aksoy L. Anti-inflammatory effects of royal jelly on ethylene glycolinduced renal inflammation in rats. Res J Pharm Sci. 2015;2:1-4. DOI: $10.1590 /$ S1677-5538.IBJU.2014.0470

4. Sridharan B, Micheal ST, Ramachandran A, Ganesh RN, Viswanathan P. Citrus bioflavonoids ameliorate hyperoxaluria induced renal injury and calcium oxalate crystal deposition in Wistar rats. Adv Pharm Bull. 2015;5:1-9. DOI: $10.15171 /$ apb.2015.057

5. Martusevich AK, Kozlova LM. Possibilities of urolithiasis crystallo diagnostics. Iraqi J Vet Sci. 2017;31(1):23-27. DOI: 10.33899/ijvs.2017.126706

6. Rajput P, Chaudhary M, Sharma RA. Phytochemical and pharmacological importance of genus urtica: A review. Int J Pharm Sci Res. 2018;9(4):1387-96.DOI: 10.13040/IJPSR.09758232.9(4).1387-96

7. Kumari J, Baunthiyal $M$ and Singh A: Characterization of silver nanoparticles synthesized using Urtica dioica leves and their synergistic effects with antibiotics. J Radiat Res Appl Sci. 2016;9(3):217-227. DOI: $10.1016 /$ j.jrras.2015.10.002

8. Joshi BC, Mukhija M, Kalia A N. Pharmacognostical review of Urtica dioica L. Inter J Green Pharm. 2014;8(4). DOI: $10.22377 /$ ijgp.v8i4.414

9. Woodland DW. Biosystematics of the perennial north American taxa of urtica. II. Taxonomy. Systc Bot. 1982;7(3):282-290. DOI: $\underline{10.2307 / 2418389}$

10. Abed Al-Saadon MB. Isolation of some compounds from celery (Apium graveolens) seeds and studying their effects in mice exposed to oxidative stress [PhD dissertation]. Mosul: College of Education. University of Mosul, Mosul, Iraq; 2005.

11. Mohammed IH, Kakey ES. Effect of Prosopis farcta extracts on some complications (hematology and lipid profiles) associated with alloxan induced diabetic rats. Iraqi J Vet Sci. 2020;34(1):45-50. DOI: 10.33899/ijvs.2019.125574.1089

12. Karadi R, Gadge N, Savadi R. Effect of Moringa oleifera Lam. rootwood on ethylene glycol induced urolithiasis in rats. J Ethnopharm. 2006;105:306-11. DOI: 10.1016/j.jep.2005.11.004

13. Kafi LA, Kbyeh FR. Prophylactic role of sweet almond (Prunus amygdalus) suspension in healthy and experimentally induced diabetic rats. Iraqi J Vet Sci. 2020;34(1):59-64. DOI: 10.33899/ijvs.2020.164357

14. Culling CFA. Handbook of histopathological and histochemical techniques. $3^{\text {rd }}$ ed. London: Butterworths. 1974. DOI: 10.1016/C20130-04011-X

15. Al-Mahmood SS. Improving light microscopic detection of collagen by trichrome stain modification. Iraqi J Vet Sci. 2020;34(2):473-481. DOI: 10.33899/ijvs.2020.126176.1256

16. Al-Jammas S, Al-Saraj A. The histological changes induced by cytarabine on rabbits livers (with and without vitamin $\mathrm{E}$ administration). Iraqi J Vet Sci. 2020;34(1):9-13. DOI: 10.33899/ijvs.2020.163564

17. Tsujihata M. Mechanism of calcium oxalate renal stone formation and renal tubular cell injury. Int $J$ Urol. 2008;15(2):115-20. DOI: 10.1111/j.1442- 2042.2007.01953.x

18. Tugcu V, Kemahli E, Ozbek E, Arinci YV, Uhri M, Erturkuner P, Metin G, Seckin I, Karaca C, Ipekoglu N, Altug T, Cekmen MB, Tasci AI. Protective effect of a potent antioxidant, pomegranate juice, in the kidney of rats with nephrolithiasis induced by ethylene glycol. J Endourol. 2008;22(12):2723-31. DOI: 10.1089/end.2008.0357

19. Ingale KG, Prasad A, Thakurdesai PA, Vyawahare NS. Effect of Hygrophila spinosa in ethylene glycol induced nephrolithiasis in rats.
Indian J Pharmacol. 2012;44(5):639-642. DOI: 10.4103/02537613.100402

20. Agawane SB, Gupta VS, Kulkarni MJ, Bhattacharya AK, Koratkar SS, Rao VK. Patho-physiological evaluation of Duranta erecta for the treatment of urolithiasis. J Ayurveda Integrat Med. 2019;10:4-11. DOI: 10.1016/j.jaim.2017.08.001

21. Ghelani H, Chapala M, Jadav P. Diuretic and antiurolithiatic activities of an ethanolic extract of Acorus calamus L. rhizome in experimental animal models. J Trad Compl Med. 2016;6(4):431-436. DOI: 10.1016/j.jtcme.2015.12.004

22. Al-Assaf IN, Al-Dabbagh AA, Al-Abachi RY, Al-Bajari SA. Protective role of Urtiea dicica on the pathological alteration induced by ethylene glycol. Sys Rev Pharm. 2020;11(12):1180-1183. DOI: 10.31838/srp.2020.12.172

23. Abdul Wahab SM, Jantan I, Haque MA, Arshad L. Exploring the leaves of Annona muricata L. as a source of potential antiinflammatory and anticancer agents. Front Pharmacol. 2018;9:661. DOI:10.3389/fphar.2018.00661

24. Thapa BR, Walia A. Liver function tests and their interpretation. Indian J Pediatr. 2007;74(7):663-671. DOI: 10.1007/s12098-0070118-7

25. Ozturk H, Cetinkaya A, Firat TS, Tekce BK, Duzcu SE, Ozturk H. Protective effect of pentoxifylline on oxidative renal cell injury associated with renal crystal formation in a hyperoxaluric rat model. Urolithiasis. 2019;47(5):415-424. DOI: $\underline{10.1007 / \mathrm{s} 00240-018-1072-8}$
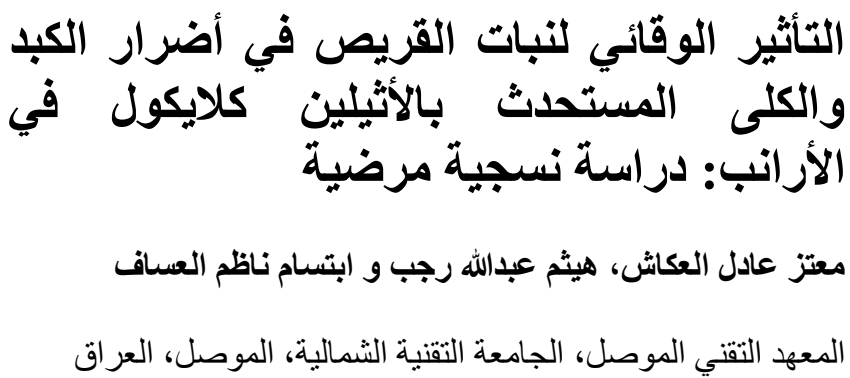

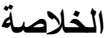

يستخدم نبات القريص في العديد من البلدان بشكل نو ابل أو دواء أواء

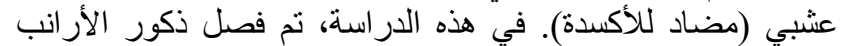

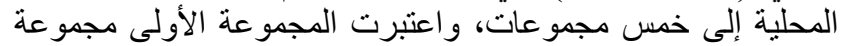

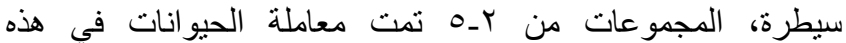

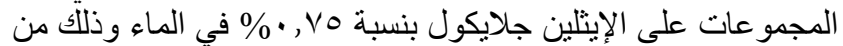

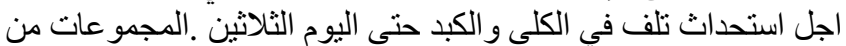

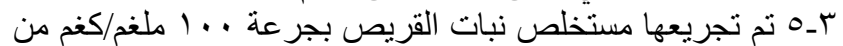

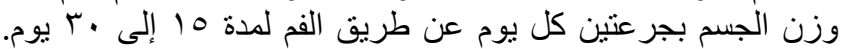

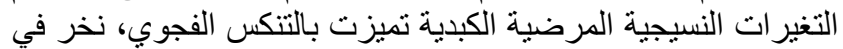

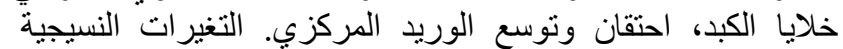

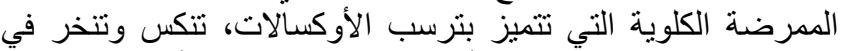

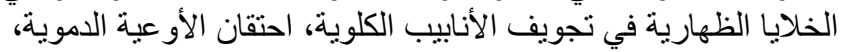

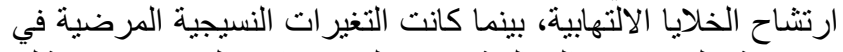

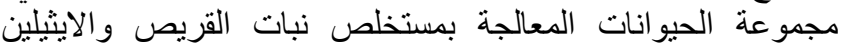

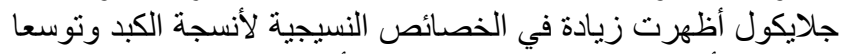

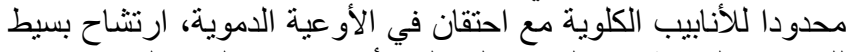

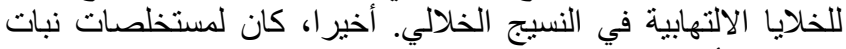
القريص تأثثير محسن للتغيرات النسيجية الكبدية والكلوية التي يسبيها لالتيات

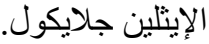

